\title{
Far-Field Simulation of the Hawaiian Wake: Sea Surface Temperature and Orographic Effects*
}

\author{
JAN HAFNER \\ International Pacific Research Center, University of Hawaii at Manoa, Honolulu, Hawaii \\ SHANG-PING XIE \\ International Pacific Research Center, and Department of Meteorology, University of Hawaii at Manoa, Honolulu, Hawaii
}

(Manuscript received 8 October 2002, in final form 16 July 2003)

\begin{abstract}
Recent satellite observations reveal far-reaching effects of the Hawaiian Islands on surface wind, cloud, ocean current, and sea surface temperature (SST) that extend leeward over an unusually long distance $(>1000 \mathrm{~km})$. A three-dimensional regional atmospheric model with full physics is used to investigate the cause of this long wake. While previous wind-wake studies tend to focus on regions near the islands, the emphasis here is the far-field effects of SST and orography well away from the Hawaiian Islands. In response to an island-induced SST pattern, the model produces surface wind and cloud anomaly patterns that resemble those observed by satellites. In particular, anomalous surface winds are found to converge onto a zonal band of warmer water, with cloud liquid water content enhanced over it but reduced on the northern and southern sides. In the vertical, a two-cell meridional circulation develops of a baroclinic structure with the rising motion and thicker clouds over the warm water band. The model response in the wind and cloud fields supports the hypothesis that oceanatmosphere interaction is crucial for sustaining the island effects over a few thousand kilometers.

Near Hawaii, mountains generate separate wind wakes in the model lee of individual islands as observed by satellites. Under orographic forcing, the model simulates the windward cloud line and the southwest-tilted cloud band leeward of the Big Island. In the far field, orographically induced wind perturbations are found to be in geostrophic balance with pressure anomalies, indicative of quasigeostrophic Rossby wave propagation. A shallowwater model is developed for disturbances trapped in the inversion-capped planetary boundary layer. The westward propagation of Rossby waves is found to increase the wake length significantly, consistent with the threedimensional simulation.
\end{abstract}

\section{Introduction}

Flow perturbed by mountains has been a classic subject of fluid mechanics and meteorology. The advent of satellite observations reveals spectacular vortex streets behind elevated islands as visualized by low clouds, adding further fascination to this classic problem (e.g., Scorer 1986; Thomson et al. 1977). Stratification and mountain height $(h)$ are generally important for determining the flow regimes, which are often measured by a nondimensional inverse Froude number $N h / U$, where $N$ is the Vaisala frequency and $U$ the ambient wind speed. In a two-dimensional flow, the upstream flow

\footnotetext{
* International Pacific Research Center Contribution Number 218 and School of Ocean and Earth Science and Technology Contribution Number 6220.
}

Corresponding author address: Dr. Jan Hafner, International Pacific Research Center, University of Hawaii at Manoa, 1680 East West Road, Honolulu, HI 96822.

E-mail: jhafner@hawaii.edu may be blocked for $U / N h<1 ; U^{2}=N^{2} h^{2}$ is the minimum kinetic energy necessary for an air parcel to overcome the gravity potential energy and reach the mountain top (Baines 1987). Three-dimensional flow behaves very differently. Impinging on an isolated mountain, the flow may go above or around the obstacle, depending on the stratification and maximum elevation. For example, the Hawaiian islands of Kauai and Hawaii are in a similar environment of the northeast trade winds with a temperature inversion $2-3 \mathrm{~km}$ high. Kauai Island is $1.5 \mathrm{~km}$ tall and the trade winds flow over the mountains. As a result, the maximum rainfall at a climatological rate of $11500 \mathrm{~mm} \mathrm{yr}^{-1}$ takes place at the summit, making it one of the wettest spots on earth (Giambelluca and Schroeder 1998). By contrast, the island of Hawaii (hereafter the Big Island) stands far above the inversion, forcing the winds to go around the high mountains (see Fig. 1a). At the summit of Mauna Kea (4.2 km above sea level), the annual rain rate is below $50 \mathrm{~mm} \mathrm{yr}^{-1}$, whereas relatively large rainfall $\left(300-600 \mathrm{~mm} \mathrm{yr}^{-1}\right)$ is observed on the windward side and northern and southern flanks. 

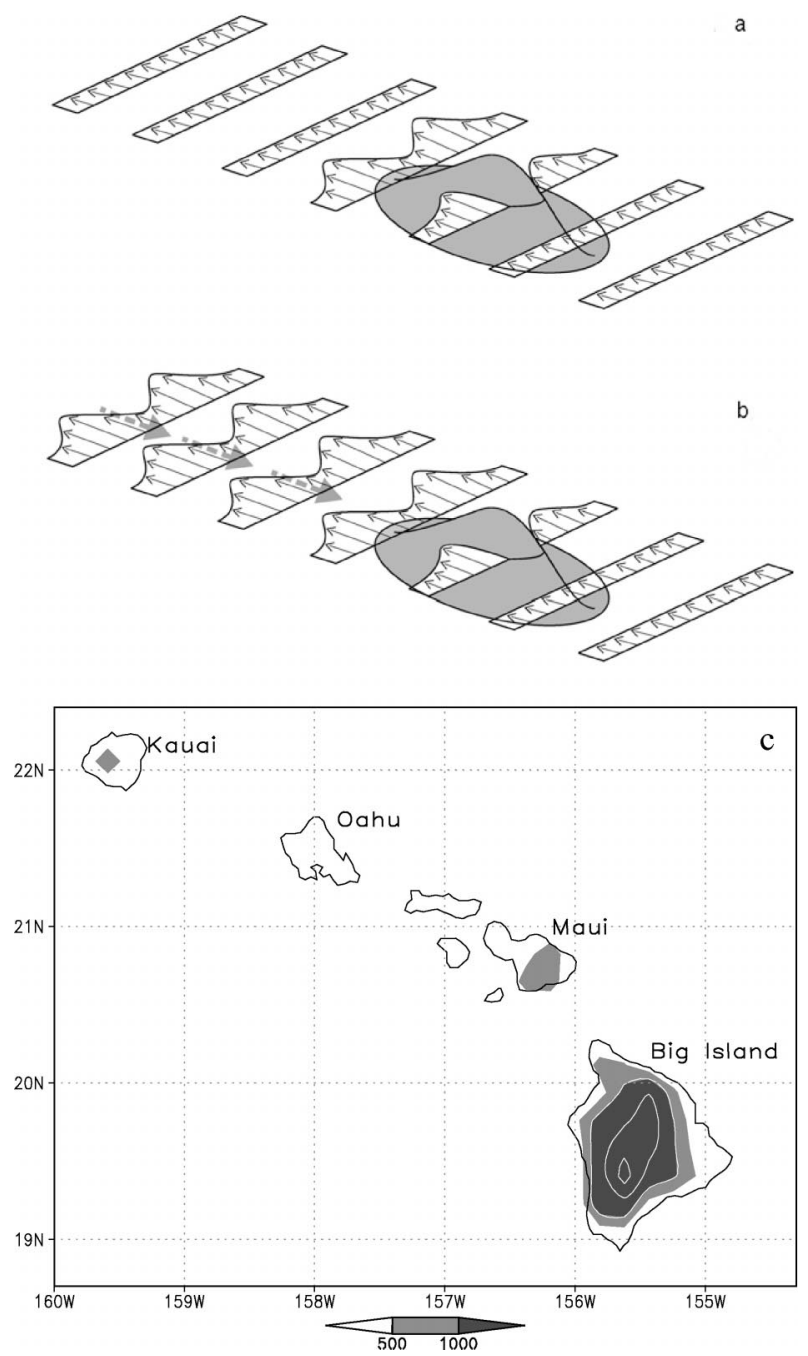

FIG. 1. Schematics for (a) a traditional conceptual model of a wind wake with no oceanic response and (b) the Hawaiian wake. Dark broken arrows denote the eastward HLCC that advects warm water toward Hawaii. (c) Model topography: the contours start at $1000 \mathrm{~m}$ and the interval is $1000 \mathrm{~m}$

Regardless the flow regimes, a zone of weak wind almost always forms leeward of an elevated island. Far away from other landmasses and sitting in the calm subtropical high with the steady trade winds, the Hawaiian Islands are an ideal natural laboratory for studying island wake phenomena. The wind wake of the Big Island has been the subject of previous aircraft field campaigns. Nickerson and Dias (1981) utilized data from the Hawaii Mesoscale Energy and Climate (HAMEC) program and detected a pair of vortices. Based on theoretical considerations, they estimated a vortex shedding frequency of about $32 \mathrm{~h}$ but could not confirm it from observations. Smith and Grubišić (1993) utilized observations collected during the Hawaiian Rain Band Project (HaRP) and analyzed the flow in the wake. From aerial measurements, they found two counterrotating lee eddies with a strong return flow on the wake's center axis extending about $200 \mathrm{~km}$ westward (downstream). The wake and its eddies seemed quasi-stationary. The air in the vortices was observed to be warmer and drier than upstream. The authors also observed weak hydraulic jumps along the north and south tips of the Big Island.

Some numerical models predict an unstable wake of the Big Island and shed eddies leeward (Smolarkiewicz et al. 1988; Ueyoshi and Han 1991), but some models produce a steady wake (Reisner and Smolarkiewicz 1994). Grubišić et al. (1995) use a shallow-water model and discuss the instabilities of the Hawaiian wake. Another focus for modeling airflow around the Big Island has been the windward cloud band (Smolarkiewicz et al. 1988), which seems sensitive to the trade inversion height and to a lesser extent to diurnal solar heating (Chen and Feng 2001).

While all the above studies focus on the near-field $[O(100) \mathrm{km}]$ effects of island mountains, based on new microwave measurements by the Quick Scatterometer (QuikSCAT) and Tropical Rain Measuring Mission (TRMM) satellites, Xie et al. (2001) report far-field effects of the Hawaiian Islands on wind curl and cloud liquid water that extend beyond the international date line for more than $3000 \mathrm{~km}$. Noting in the electronic supplement that the length of this Hawaiian wake is one order of magnitude greater than the Smith et al. (1997) theory, Xie et al. (2001) suggest the following air-sea interaction scenario. In traditional studies of island wakes, the ocean and its sea surface temperature (SST) are considered unchanged. The aerodynamic effect of the mountains dissipates in a few hundred kilometers downstream due to surface drag and mixing with the ambient air and across the inversion (Smith et al. 1997). Near Hawaii, the trade winds are steadily present throughout the year, and the meridional span of the island chain is greater than the oceanic radius of deformation $(<100 \mathrm{~km})$. The wind curl in the wind wake thus acts as a steady forcing onto the ocean, inducing a longwave Rossby response that is accompanied by an eastward current called the Hawaiian Lee Counter Current (HLCC; the broken arrow in Fig. 1b). Flowing against the easterly trades, the HLCC is observed from the surface drifter (Qiu et al. 1997; Flament et al. 1998) and hydrographic (Xie et al. 2001; Kobashi and Kawamura 2001) measurements. It advects the warmer water from the western Pacific, forming a warm tongue directing toward Hawaii in the SST distribution. This warm water band causes the surface wind to converge onto it, sustaining the spatial variations in wind and cloudiness for thousands of kilometers. This SST modulation of wind and cloud is a key assumption in Xie et al.'s (2001) scenario of air-sea interaction, one that seems consistent with their satellite observations but has not been rigorously tested. Such interaction with the ocean is perhaps a unique aspect of the Hawaiian wake, made possible by the presence of the steady and strong trade winds, high mountains, and the relative large size 
of the island chain, conditions for island-induced wind curls to excite nondispersive long Rossby waves in the ocean.

The present study investigates the role of SST in extending the influence of the Hawaiian Islands on the trade wind system in the western North Pacific by using a high-resolution regional atmospheric model. We first compare the model simulation with available satellite observations. In the event of a favorable comparison, we will examine the vertical structure of the model response to the Hawaii-induced SST variations to further understand the adjustment processes, a study that twodimensional satellite observations do not allow.

Previous studies have yielded a great deal of understanding toward the hydrodynamics of island wakes such as the vorticity generation and stability, but they all tend to focus on the near field on the order of 100 $\mathrm{km}$ in the vicinity of islands. The study of Smith et al. (1997) is an exception. By considering a balance between the advection and surface drag in the momentum equation, they arrive at an $e$-folding scale for the decay of the wind wake $L=H /\left(2 C_{D}\right)$; here, $H$ is the inversion height and $C_{D}$ is the aerodynamic drag coefficient. Smith et al. (1997) show that $L$ represents the decay of wind deficit-the speed difference between then ambient and wake-rather well in a fully nonlinear shallow-water model. This damping scale, however, neglects the effects of pressure adjustment and earth rotation that are likely important for large-scale mountains in Hawaii. Using a large model domain $(2500 \mathrm{~km}$ in the east-west direction), we examine the far-field adjustment of the trade wind system to the perturbation of the Hawaiian mountains. We show that wind perturbations are roughly in geostrophic balance with pressure anomalies indicative of orographically forced Rossby waves.

The rest of the paper is organized as follows. Section 2 describes the model physics and setup. Section 3 discusses the results from the control simulation. Sections 4 and 5 investigate the SST and orographic effects, respectively. Section 6 is a summary.

\section{Model}

We use a regional atmospheric model developed at the National Center for Atmospheric Research (NCAR) and the Pennsylvania State University (PSU): the fifth generation of the PSU-NCAR mesoscale model (MM5; Dudhia 1993; Grell et al. 1994) version 3.4. It solves nonhydrostatic primitive equations in the vertical sigma$p$ coordinate, with multiple options for radiation, cumulus, microphysics, and boundary layer parameterizations. The model is well tested and widely applied to various research problems including flow around Hawaii (Cheng and Feng 2001; Businger et al. 2002). After having tested several combinations of parameterizations, we chose the following set of parameterizations: the Kain-Fritsch (Kain and Fritsch 1993) cumulus parameterization for subgrid processes, Goddard modified explicit microphysics (Lin et al. 1983) for grid-scale processes, Hong and Pan (1996) medium-range forecast (MRF) boundary layer scheme, and a five-layer simple soil model. The Rapid Radiative Transfer Model (RRTF; Mlawer et al. 1997) was selected for radiation calculations. Here the selection of the soil model is unimportant as most of the domain is covered by sea.

The model domain extends from $14.5^{\circ}$ to $27.5^{\circ} \mathrm{N}$ and $175^{\circ}$ to $149^{\circ} \mathrm{W}$, centered at $21^{\circ} \mathrm{N}, 161^{\circ} \mathrm{W}$ with a grid spacing of $27 \mathrm{~km}$. To resolve the trade inversion, we use 36 sigma levels and place 16 of them below sigma $=0.8$. The model sigma levels are 0.99, 0.98, 0.97, $0.96,0.95,0.94,0.93,0.92,0.91,0.90,0.885,0.87$, $0.885,0.84,0.825,0.81,0.795,0.78,0.765,0.75,0.735$, $0.72,0.705,0.69,0.675,0.66,0.645,0.63,0.615,0.55$, $0.50,0.40,0.30,0.20,0.10$, and 0.00 . As initial and lateral boundary conditions, we use the National Centers for Environmental Prediction (NCEP) analysis data available at a $2.5^{\circ} \times 2.5^{\circ}$ grid in horizontal and at the mandatory levels in vertical (surface, 1000, 850, 700, 500, $400 \mathrm{mb} .$. .).

Weekly SST measurements by the TRMM Microwave Imager (TMI) are used as the surface boundary condition. Weekly TMI-derived SST fields were used to construct model's bottom boundary conditions by interpolating from the $0.25^{\circ}$ latitude $\times 0.25^{\circ}$ longitude grid to the model's $27-\mathrm{km}$ nest. Following Xie et al. (2001), we apply a low-pass filter of $4^{\circ}$ running mean in the meridional direction to remove the effect of the Hawaiian Islands and use this low-pass-filtered SST in our control run. We perform two additional experiments by adding a pair of warm and cold SST bands to mimic the thermal advection by ocean currents (the SST run) and by removing all the topography on the islands [the no-mountain (NM) run]. Each simulation lasts for a month from 1 to 31 August 1999. The first 3-day data are discarded and data are averaged over the last 28 days of the simulations for the following analyses.

For comparison, we use the TMI measurements of vertically integrated water vapor and cloud liquid water (Wentz et al. 2000) and QuikSCAT wind velocity dataset (Liu et al. 2000), both available at the $0.25^{\circ}$ resolution.

\section{Control run}

Figure 2 compares the MM5 wind velocity at $10 \mathrm{~m}$ with the QuikSCAT winds (scaled to 10-m height and neutral stratification) near Hawaii. The simulation of the large-scale wind direction and speed is quite good. In both the model and observations, the strongest winds are found between Maui and the Big Island, two islands of maximum elevation above $3 \mathrm{~km}$. The strong wind south of the Big Island is also reproduced in the model. The reduction in wind speed in the Big Island wake is much more pronounced in the model than in the QuikSCAT map. The model produces a weak return flow in the wake as observed in Smith and Grubišić's (1993) aircraft surveys. The lee vortices appear to be quasi- 

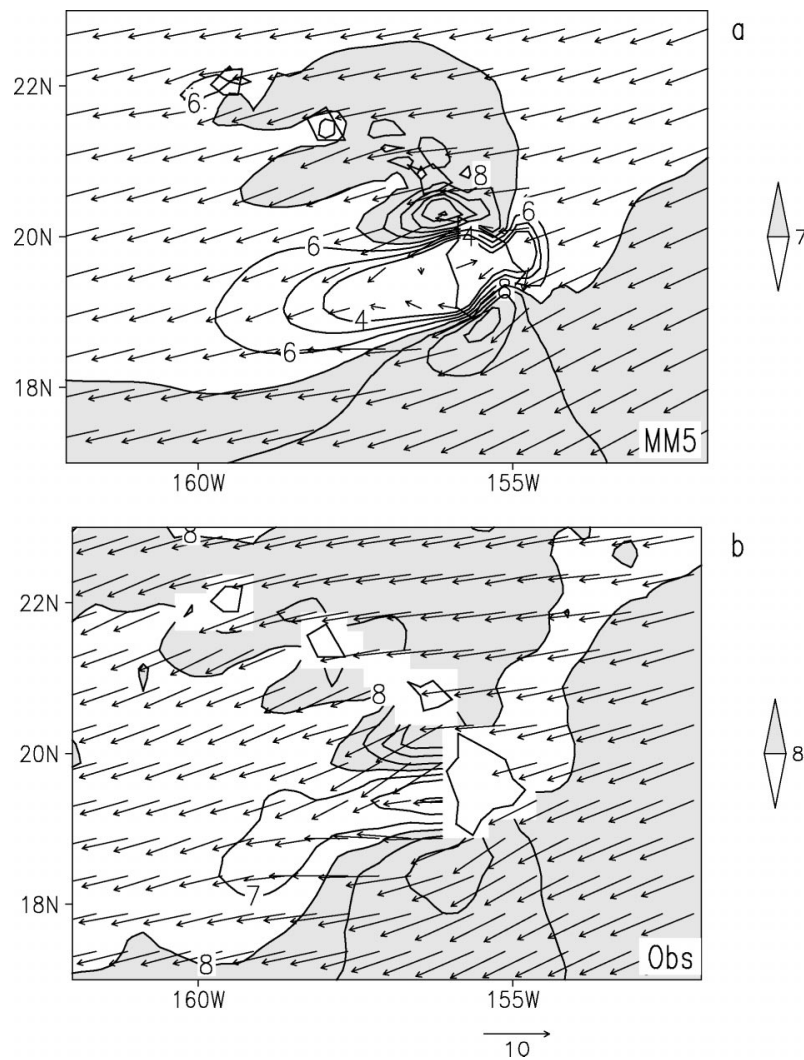

FIG. 2. Surface wind speed (contours) and velocity (vectors) (a) modeled by MM5 and (b) observed by QuikSCAT. The contour interval is $1 \mathrm{~m} \mathrm{~s}^{-1}$ and contours with values smaller than $4 \mathrm{~m} \mathrm{~s}^{-1}$ are omitted. MM5 and QuickSCAT winds are averages for 4-31 Aug 1999.

stationary and subject to deformation due to upstream flow perturbations. Periodic shedding of the vortices that some previous studies predicted (Nickerson and Dias 1981; Smolarkiewicz et al. 1988) is not detected in our model simulation. This is consistent with Smith and Grubišić's (1993) observations, but may be a model artifact due to the coarse resolution $(27 \mathrm{~km})$ that does not resolve the details of Big Island mountains and shed eddies.

The QuikSCAT data do not show such a reversal of flow. Similarly, the island blocking windward of the Big Island is much stronger in the model than in the QuikSCAT map. These differences may be due to the model errors or alternatively due to the retrieval problem with the satellite scatterometer near the landmass. The former seems unlikely because we used smoothed topography in the model, which should underestimate the orographic effect if anything. Wind wakes of other major Hawaiian islands are visible in the model simulation but weaker than in the QuikSCAT measurements, most likely due to the underrepresentation of orographic effects of these smaller islands in this model of $27-\mathrm{km}$ resolution. The aerodynamic effect of islands apparently decays away in 200-400 km, consistent with the Smith

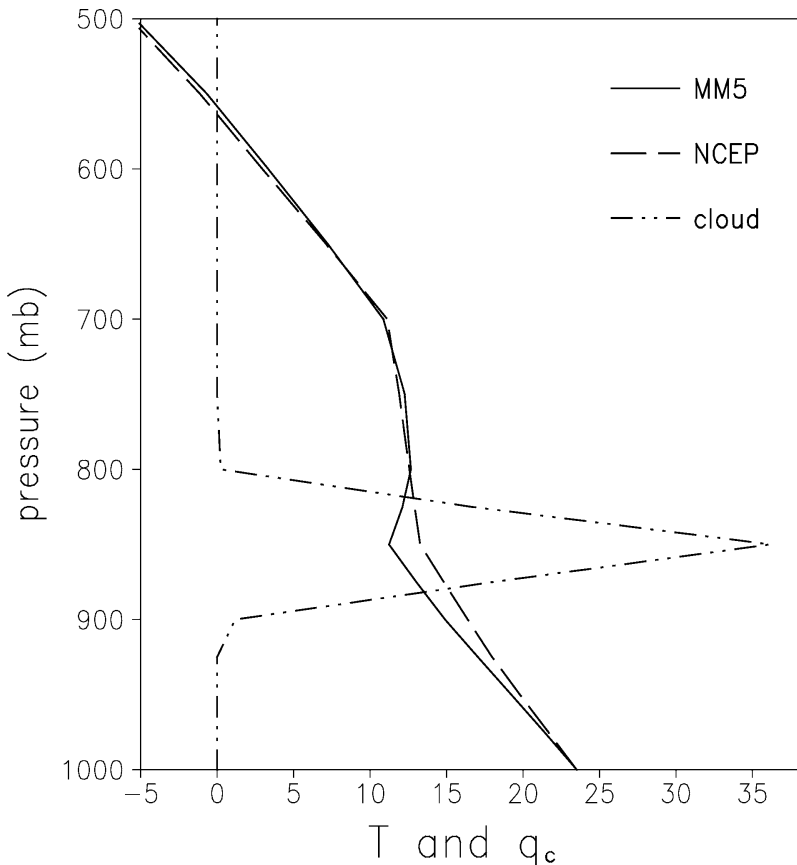

Fig. 3. Vertical profiles of daily average temperature $\left({ }^{\circ} \mathrm{C}\right)$ and cloud liquid water content $\left(10^{-2} \mathrm{~g} \mathrm{~kg}^{-1}\right)$ as simulated by the MM5 on 24 Aug 1999 at $20.8^{\circ} \mathrm{N}, 152.3^{\circ} \mathrm{W}$ (upstream from Big Island). The dotted line represents the NCEP temperature profile.

et al. (1997) theory. We will return to this orographic effect in section 5 .

The inversion is an important feature of the subtropical North Pacific atmospheric boundary layer that we have taken pains to simulate in the MM5. It provides strong buoyancy stratification and a waveguide for horizontal propagation of orographic disturbances. In fact, shallow-water/reduced-gravity models are often used to study island wakes (Grubišić et al. 1995; Smith et al. 1997). Because of the coarse vertical resolution, the NCEP analysis does not have a temperature inversion. But the MM5 generates and maintains a pronounced inversion by the model physics throughout the simulation period. Figure 3 shows the daily average temperature profiles on 24 August in the NCEP analysis and the MM5 at an upstream location from the Big Island. It clearly shows the capability of the model of simulating the trade inversion. On average, the model inversion is located around $800 \mathrm{mb}$ as in observations. A cloud layer is almost always found around and beneath the inversion, suggesting their coupling as is depicted in Fig. 3. Strong longwave radiation at the cloud top acts to cool the boundary layer air, while the resultant strong stratification acts to trap the moisture in the PBL and thereby helps cloud formation.

The simulated column-integrated water vapor compares well with the TMI measurements (not shown). But the model overestimates the amount of cloud liquid water compared with TMI, a problem possibly due to the use of explicit microphysics on the grid scale of 27 
$\mathrm{km}$. But the simulated strength of the inversion - a result of interaction with boundary layer clouds-is not too strong compared with Hilo soundings. We leave this simulation of the mean cloud field as a subject of future studies but note that the simulated cloud response to SST changes and orography seems to compare reasonably well with satellite observations (sections 4 and 5).

\section{SST effect}

An eastward current (HLCC) is observed west of Hawaii centered at $19.5^{\circ} \mathrm{N}$ (Qiu et al. 1997; Flament et al. 1998). Xie et al. (2001) propose that the HLCC is driven by an orographically induced wind curl of Hawaii and reproduce the current in a hierarchy of ocean models (see also Kobashi and Kawamura 2001; Liu et al. 2003; $\mathrm{Yu}$ et al. 2003). In addition to this warm current that advects the warmer western North Pacific water, the curl of the Big Island wind wake also acts to accelerate the westward North Equatorial Current (NEC) to the south that advects the colder eastern Pacific water. Two bands of warm and cold SST are imposed on the meridionally smoothed SST field used in the control run (Fig. 4a), each $4^{\circ}$ wide and oriented in the zonal direction, to mimic the thermal advection by the HLCC and accelerated NEC to the south, respectively. The imposed SST perturbation has a sine wave form given by

$$
\Delta \mathrm{SST}=\sin \left(\pi \frac{y-y_{o}}{L_{y}}\right) \text { for }\left|y-y_{o}\right| \leq L_{y},
$$

where $y_{o}=17.5^{\circ}$ and $L_{y}=4^{\circ}$ is the meridional width of each anomalous SST band. The maximum SST anomaly is $1^{\circ} \mathrm{C}$ in the model, about a factor of 3 greater than in observations (Fig. 4b). This is to enhance the atmospheric response to SST forcing and hence increase the signal-to-noise ratio in the model. As will be seen, the atmospheric response is not very large even to this enhanced SST forcing. For example, the surface wind anomalies are on the order of $1 \mathrm{~m} \mathrm{~s}^{-1}$. With such modest amplitudes, the atmospheric response is likely to be in the linear regime, increasing in proportion with the size of imposed forcing. [The numerical study by Tompkins and Craig (1999) seems to support this linearity of atmospheric response to SST perturbations.] To the extent that this linear regime holds, we may infer the magnitude of realistic response by scaling the model results properly. Unless stated otherwise, we discuss the SST effect based on this SST run with the idealized SST forcing.

As Xie et al. (2001) argue, the response to orographic effect of Hawaii is intrinsically coupled and involves air-sea interaction. While the first response of the ocean to island-induced wind curls indeed propagates westward as nondispersive long Rossby waves, it will induce atmospheric changes in wind stress and surface heat flux that in turn affect the ocean. This fully coupled problem is beyond the scope of this study, which is rather limited
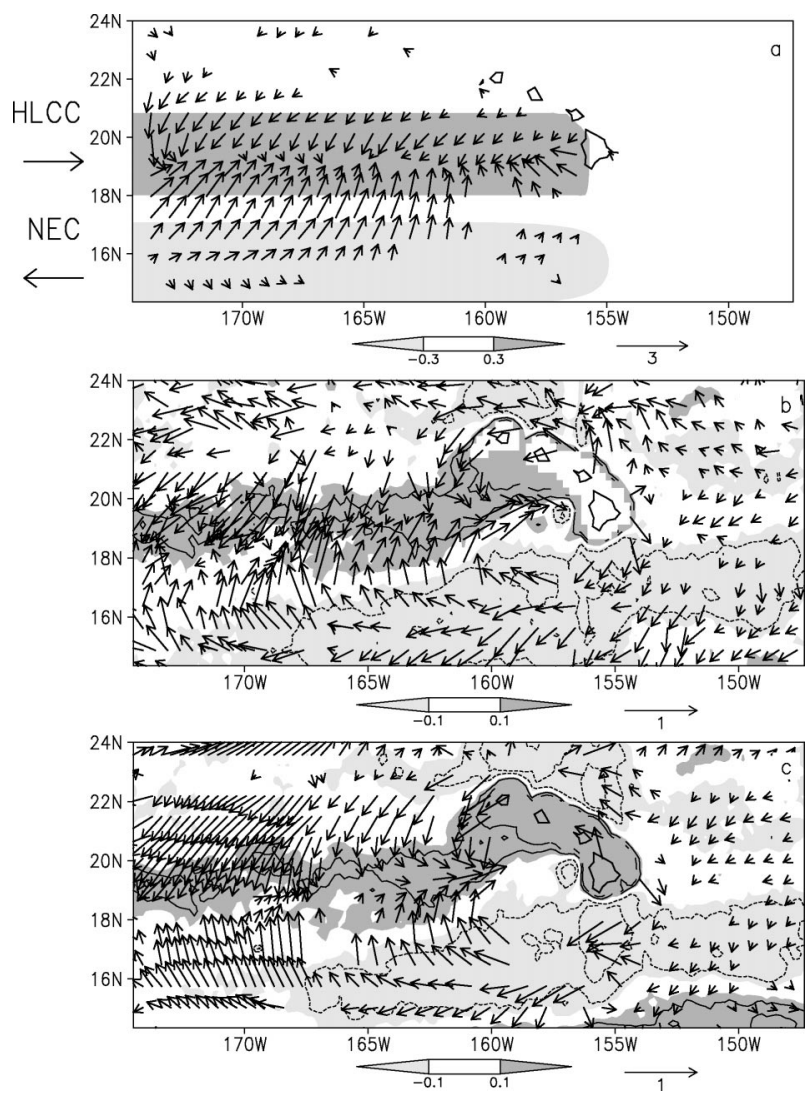

FIG. 4. (a) Surface wind response to enhanced SST forcing with the cold and warm SST bands shaded. (b) TRMM SST and QuikSCAT surface wind that are high-pass-filtered in the meridional direction following Xie et al. (2001) and averaged for 21 Jul-31 Oct 1999. Contour interval in (b) is $0.2^{\circ} \mathrm{C}$ with the zero line omitted and negative values dashed. (c) The same as (b), but for MM5-modeled winds in the observed SST run (realistic SST). The wind vectors east of $167^{\circ} \mathrm{W}$ are scaled down by a factor of 2 for clarity.

to the relevant atmospheric processes. By specifying the zonal SST bands, our model results may be viewed as representing the first atmospheric reaction to the passage of ocean Rossby waves. We will, however, make inferences on the how this atmospheric reaction might feedback on the ocean in section $4 \mathrm{c}$.

\section{a. Wind response}

Figure 4a depicts the surface wind response to the banded SST structure. The anomalous surface winds converge (diverge) over the warm (cold) band, with southwesterly (northeasterly) anomalies south (north) of the warm SST band. Overall, the surface wind response resembles the meridionally high-pass-filtered wind anomalies except in the vicinity of Hawaii where the direct orographic effect dominates (Fig. 4b).

The idealized anomalous SST pattern in Fig. 4a does not allow a direct comparison with observations. We have performed an additional simulation, the same as the SST run except using the observed TMI SST av- 

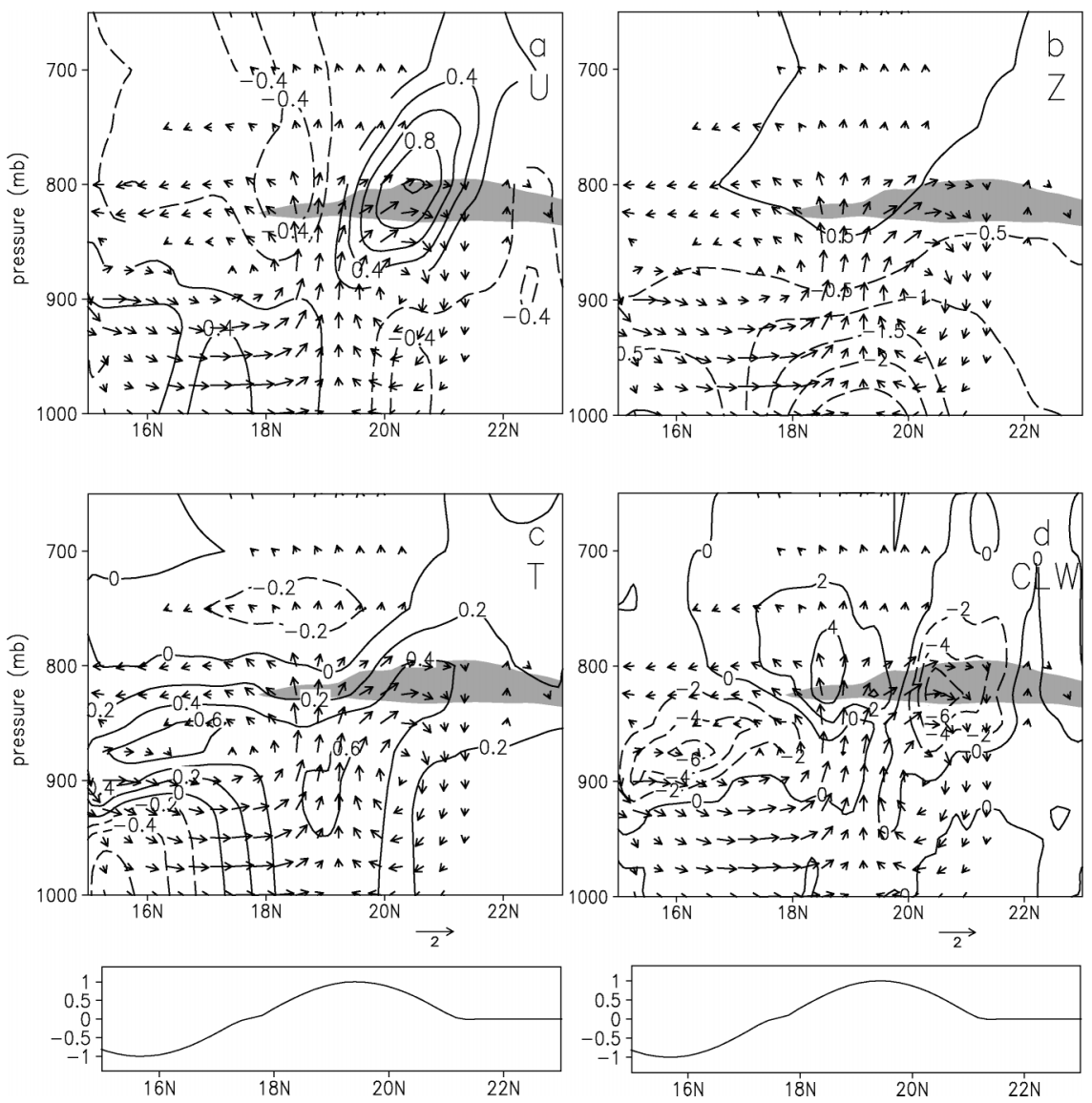

FIG. 5. Atmospheric response to the idealized SST forcing averaged zonally between $167^{\circ}$ and $162^{\circ} \mathrm{W}$ : (a) zonal wind $\left(\mathrm{m} \mathrm{s}^{-1}\right)$, (b) geopotential height (m), (c) air temperature $\left({ }^{\circ} \mathrm{C}\right)$, and (d) cloud liquid water content $\left(\mathrm{g} \mathrm{kg}^{-1}\right)$. The shaded area represents the trade inversion, wind vectors are meridional $\left(\mathrm{m} \mathrm{s}^{-1}\right)$ and vertical $\left(\mathrm{cm} \mathrm{s}^{-1}\right)$ wind components. Imposed SST anomalies are given at the bottom.

eraged for 21 July-31 October 1999 (the same SST field used to generate Fig. $4 \mathrm{~b}$ ) as the boundary condition. Figure $4 \mathrm{c}$ shows surface winds and SST that are meridionally high-pass-filtered in the same way as in Fig. 4b. (The slight differences in the filtered SST from Fig. $4 \mathrm{~b}$ are artifacts due to the north and south boundaries of the model.) Away from its northern boundary, the model reproduces the QuikSCAT observations quite well. In particular, anomalous winds converge onto the warm band, much as in observations. In the far field (west of $165^{\circ} \mathrm{W}$ ), the wind anomaly patterns in all three panels of Fig. 4 share the same characteristic of being southwesterly south and northeasterly north of the warm SST band. This common wind pattern indicates that the observed wind anomalies in the far field are indeed the response to SST variations induced by ocean current advection. (As will be discussed in the section 5, orographically induced surface wind anomalies are weaker in the far field and nearly nondivergent.)

Figure 5 shows the vertical structure of the model response to the idealized SST perturbations, zonally averaged between $167^{\circ}$ and $162^{\circ} \mathrm{W}$. Air temperature in the planetary boundary layer (PBL) follows the underneath SST changes, with positive (negative) anomalies over the warm (cold) band. (The maximum air temperature anomaly is located slightly south of the maximum SST anomaly, an effect of southward advection by the trades). A well-organized two-cell circulation develops over the depth of the PBL, with the surface wind anomalies that converge (diverge) over the warm (cold) band. The rising motion above the warm SST band peaks at $850 \mathrm{mb}$ and decays rapidly above the inversion. The associated adiabatic cooling causes cold temperature anomalies at and above the inversion.

This dynamic response can be understood in the framework of thermally direct circulation, much like the Hadley circulation, albeit with a much reduced vertical height. Each of the three components of the anomalous wind velocity resembles those of the first-baroclinic mode with a lid at the PBL-capping inversion. The response of this three-dimensional full-physics model seems consistent with the baroclinic Matsuno (1966) and Gill (1980) model with anomalous zonal winds consistent either with the Coriolis forcing acting on the 
meridional wind or with the geostrophic balance with the geopotential gradient anomalies. Stronger zonal winds in the upper PBL despite small geopotential anomalies are probably due to weaker momentum drag there. With a Rossby radius of deformation of $4^{\circ}$ (see the appendix) that is comparable with the meridional scale of the SST perturbation, anomalies of zonal flow and geopotential are roughly in geostrophic balance.

The vertical displacement of the inversion induces temperature anomalies there of comparable magnitude but opposite signs with the anomalies near the surface. Hashizume et al. (2002) detected a similar vertical dipole of temperature anomalies in the eastern equatorial Pacific that is induced by SST variations of oceanic origin. Thus, such baroclinic response to changing SSTs appears quite common in inversion-capped PBL and cannot be captured by PBL-averaged, barotropic models of Lindzen and Nigam (1987) and Battisti et al. (1999) that are popularly used in large-scale boundary layer modeling.

\section{b. Cloud response}

Over the warm band, the anomalous rising motion transports moisture upward and increases the cloud liquid water content in the cloud layer (Fig. 5d). On both the northern and southern sides, by contrast, cloud water decreases, apparently associated with anomalous downward motion and surface divergence there. Temperature anomalies near the inversion appear partly due to the cloud-radiative forcing (Fig. 5c); on either side of the warm band, anomalous warming takes place in the 800$900-\mathrm{mb}$ layer where cloud water and hence radiative cooling are reduced.

Figure $6 \mathrm{~b}$ is a plan view of changes in column-integrated cloud water in response to imposed SST anomalies with the idealized banded structure in space. While small-scale structures are present (probably due to weather noise), zonal bands of cloud anomalies dominate. Consistent with Fig. 5d, cloud water increases over the warm SST band and decreases on its northern and southern sides. These zonal banded structures are qualitatively similar to the observed summer climatology in which cloud liquid water reaches a local maximum along $19^{\circ} \mathrm{N}$ (the latitude of the HLCC) and a meridional minimum either to the north or south (Fig. 6a). The northern minimum appears centered along $22^{\circ} \mathrm{N}$ in the far field of the observed climatology, slightly north of the negative anomaly band in the model. The southern minimum band in observations slants in a southwest direction over the similarly slanted cold-SST band. Quantitatively, the simulated anomalies are far too large because of unrealistically large SST anomalies imposed. To the extent that the linear response assumption is valid, scaling down the simulated effect of enhanced SST forcing by a factor of 3 leads to a more realistic cloud liquid water response with an amplitude of $3 \times 10^{-2}$ $\mathrm{mm}$ that is comparable with observations (Fig. 6b).

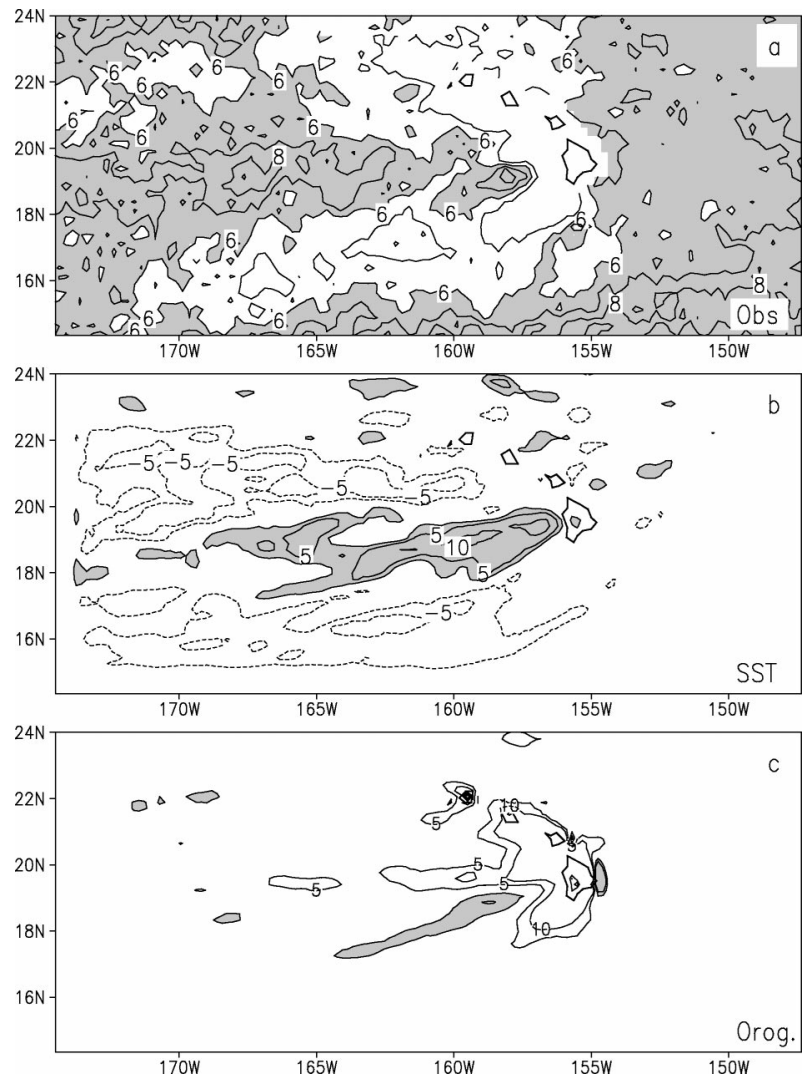

FIG. 6. Vertically integrated cloud liquid water $\left(10^{-2} \mathrm{~mm}\right)$ (a) observed by TRMM, and due to (b) enhanced SST and (c) orographics effects in the MM5. TRMM data are Jul-Sep 1999-2001 averages, and MM5 results are 4-31 Aug 1999 averages. The contour intervals are $10^{-2}$ in (a) and $5 \times 10^{-2}$ in (b). In (c) the $2.5 \times 10^{-2}$ contours are added to better show the zonally banded structure.

\section{c. Feedback onto the ocean}

Changes in cloud properties lead to changes in downward shortwave radiation at the sea surface. Figure $7 \mathrm{a}$ shows the SST and surface solar radiation differences between the SST and the control run. The thickening of clouds over the warm band reduces the solar radiation by as much as $20 \mathrm{~W} \mathrm{~m}^{-2}$, while the thinning of clouds over the cold band leads to a solar radiation increase of $40 \mathrm{~W} \mathrm{~m}^{-2}$. Obviously, the cloud response is a negative feedback on the ocean and would act to dampen the effect of ocean current advection on SST.

Latent heat flux associated with sea surface evaporation is the major mechanism for balancing the incoming solar radiation and a function of both SST and wind speed. If we neglect the difference between SST and air temperature for simplicity, latent heat flux $\left(Q_{E}\right)$ may be cast as

$$
Q_{E}=C_{E} W(1-\mathrm{RH}) q_{s}(\mathrm{~T}),
$$

where $C_{E}$ is the bulk transfer coefficient, $W$ is the wind speed, RH is the relative humidity at $10 \mathrm{~m}$, and $q_{s}(T)$ is the saturation specific humidity. For infinitesimal SST 

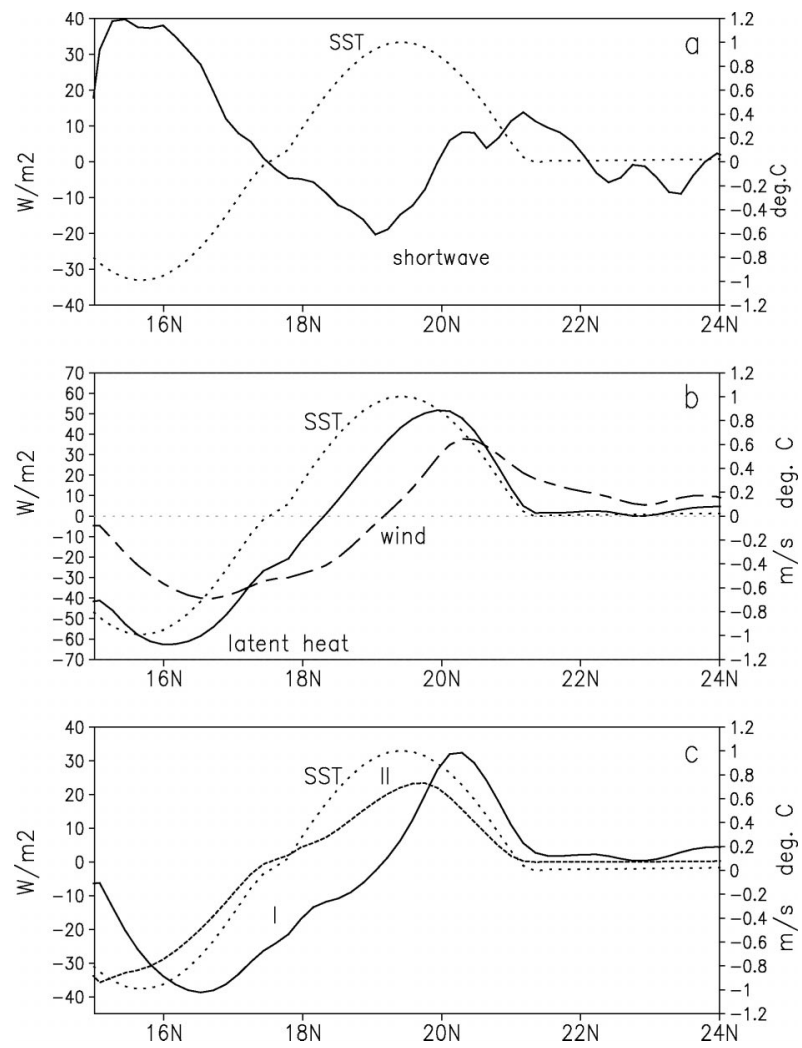

FIG. 7. Response of (a) incoming shortwave radiation, (b) wind speed and surface latent heat flux to the idealized SST forcing, (c) terms I (wind-induced latent heat) and II (Newtonian cooling) of Eq. (2) and corresponding wind and SST forcing. Values are averaged zonally between $172^{\circ}$ and $162^{\circ} \mathrm{W}$.

and wind perturbations, we may linearize the expression for $Q_{E}$ as follows:

$$
\begin{aligned}
Q_{E}^{\prime}= & \underbrace{C_{E} W^{\prime}(1-\mathrm{RH}) q_{S}(\bar{T})}_{\mathrm{I}} \\
& +\underbrace{C_{E} \bar{W}(1-\mathrm{RH}) \frac{d q_{S}(T)}{d T} T^{\prime},}_{\mathrm{II}}
\end{aligned}
$$

where the overbar and prime indicate the mean and perturbation, respectively. The first term on the rhs is the wind-induced evaporation change and the second term the Newtonian cooling due to the SST dependence. From an oceanic point of view, the first term represents the atmospheric forcing, while the second is the oceanic response.

Figure $7 \mathrm{~b}$ shows $162^{\circ}-172^{\circ} \mathrm{W}$ average anomalies of SST, wind speed, and surface latent heat flux. The anomalous southwesterly (northeasterly) winds south (north) of the warm SST band reduce (strengthen) the northeasterly trades that prevail in the background climatology. While the Newtonian cooling term (II) is roughly in phase with SST, wind-induced latent flux anomalies (term I) are negative south of the maximum SST anomaly (Fig. 7c), acting to warm SST there. This windinduced, anomalous evaporative warming would move the warm band southward if SST is allowed to change and interact with the atmosphere. Indeed, the observed warm and cold SST bands show a tendency to move southward west of Hawaii (Fig. 4b). Xie (1999) analyzes the coupled mode due to such wind-evaporation-SST (WES) feedback and shows that it propagates equatorward without external forcing. In the Hawaiian wake, the ocean current advection is the cause of the banded SST structure in the first place and anchors it where the ocean currents flow.

The anomalous wind stress distribution is similar to that of wind velocity anomalies (not shown), resulting in positive wind-stress curls over the warm band. These wind curls induce anomalous Sverdrup circulations in the ocean with westward (eastward) currents north (south) of the maximum positive SST anomaly. This dynamic response and its advective effect may be an additional mechanism for the southward shift of the observed warm band.

\section{Topographic effect}

\section{a. Wind simulation}

Here, we investigate the orographic effect of Hawaii by examining the difference fields between the control and NM runs. With the $27-\mathrm{km}$ grid spacing, the model does not resolve the details of the Hawaiian mountains, and its simulation near the islands might be questionable. This is a trade-off for our need for a large model domain. We feel that the model is adequate for a qualitative understanding of the far-field behavior of orographically induced disturbances. In particular, we are interested in how far these disturbances can propagate downstream and the mechanisms for sustaining them.

Figure 8 shows the difference fields for wind velocity and geopotential height at $800 \mathrm{mb}$ and at the surface. The mountains force a pair of strong vortices over and leeward of the islands. At the surface, a high forms on the windward side and a low on the leeward, as expected from the form drag the mountains exert on the airflow. On the leeward side, the winds adjust quickly to, and are roughly in geostrophic balance with, the pressure field about $200 \mathrm{~km}$ west of the islands. Wind anomalies are generally much stronger at $800 \mathrm{mb}$ (the inversion height) than at the surface west of $160^{\circ} \mathrm{W}$ and clearly in geostrophic balance. The prevalence of geostrophy west of $160^{\circ} \mathrm{W}$ indicates that the westward-propagating Rossby waves are the mechanism for the far-field response to orographic forcing. On the windward side, by contrast, wind and pressure are obviously not in geostrophic balance; instead, strong cross-isobaric flow appears in the model down the gradient of the windward high pressure both at the surface and $800 \mathrm{mb}$. This eastwest difference in dynamic adjustment is consistent with 

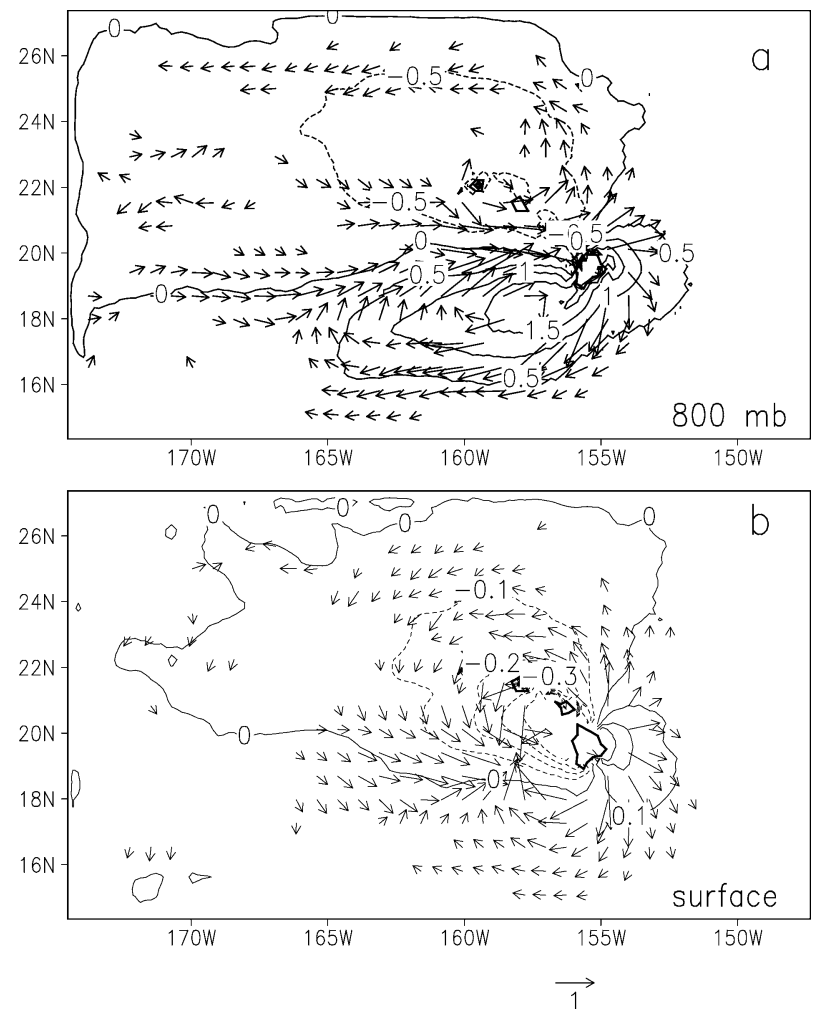

FIG. 8. Wind $z\left(\mathrm{~m} \mathrm{~s}^{-1}\right)$, geopotential height anomalies $(\mathrm{m})$, and surface pressure response $(\mathrm{mb})$ to topographic forcing at (a) $800 \mathrm{mb}$ and (b) the surface.

the westward propagation of quasigeostrophic Rossby waves. Figure 9 shows a zonally averaged vertical section of the wind wake at a sufficiently far distance from Hawaii. It confirms that the zonal wind is in geostrophic balance with the geopotential height. Unlike the baroclinic response to enhanced SST changes, the orographically forced disturbances are roughly barotropic in the vertical (see also Fig. 10a), providing justification for the (barotropic) shallow-water theory developed in the appendix. Baroclinic effect is also present, especially in the high-pressure zone south of Hawaii, where geopotential anomalies are much weaker in the PBL than in the inversion layer indicative of significant temperature anomalies in the PBL.

Figure 10a shows the wind velocity difference between the control and NM runs. Except in the vicinity of the islands, wind anomalies are confined within the PBL, indicative of the trapping effect of the inversion. Figure $10 \mathrm{~b}$ depicts the wind deficit $\left(u_{\text {control }}-u_{\mathrm{NM}}\right)$ in logarithm along the center axis of the wake. Immediately west of Hawaii, the wind deficit decays very rapidly at an $e$-folding scale of $200 \mathrm{~km}, 5$ times smaller than the theoretical estimate based on Smith et al. (1997) presumably because of much stronger dissipation in our three-dimensional, continuously stratified model. Farther to the west, the decay of the wind wake becomes much slower and seems to follow an exponential func-

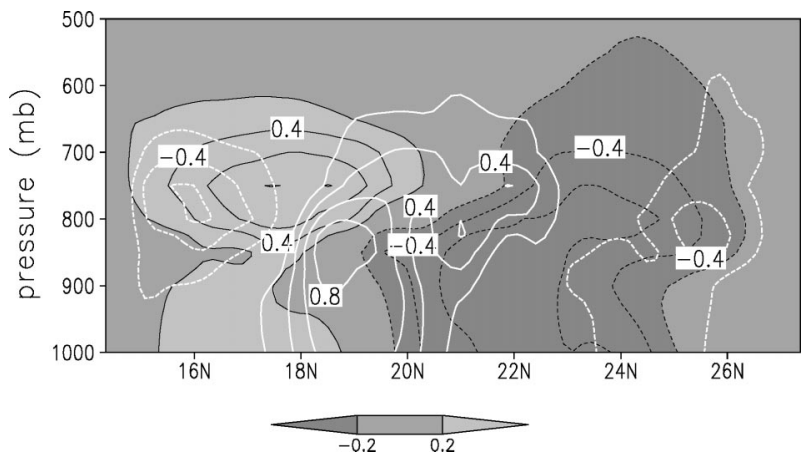

FIG. 9. Response to topographic forcing in vertical sections averaged between $166^{\circ}$ and $161^{\circ} \mathrm{W}$. Geopotential height anomalies are in black contours and shaded, and the zonal wind anomalies are in white contours. Contour intervals are $0.2 \mathrm{~m}$ for geopotential height and $0.2 \mathrm{~m} \mathrm{~s}^{-1}$ for velocity, with zero contours omitted.

tion again west of $164^{\circ} \mathrm{W}$ with an $e$-folding scale of 350 $\mathrm{km}, 75 \%$ greater than that near the islands. We interpret this slower decay in the far field as the effect of the westward-propagating Rossby waves. The appendix presents an analysis of this Rossby wave effect on wake length.

\section{b. Clouds}

Figure $6 \mathrm{~b}$ shows the difference in column-integrated cloud liquid water between the control and NM runs. Consistent with previous studies (e.g., Rasmussen et al. 1989; Austin et al. 1996; Chen and Feng 2001), the windward cloud band of the Big Island is due to oro-
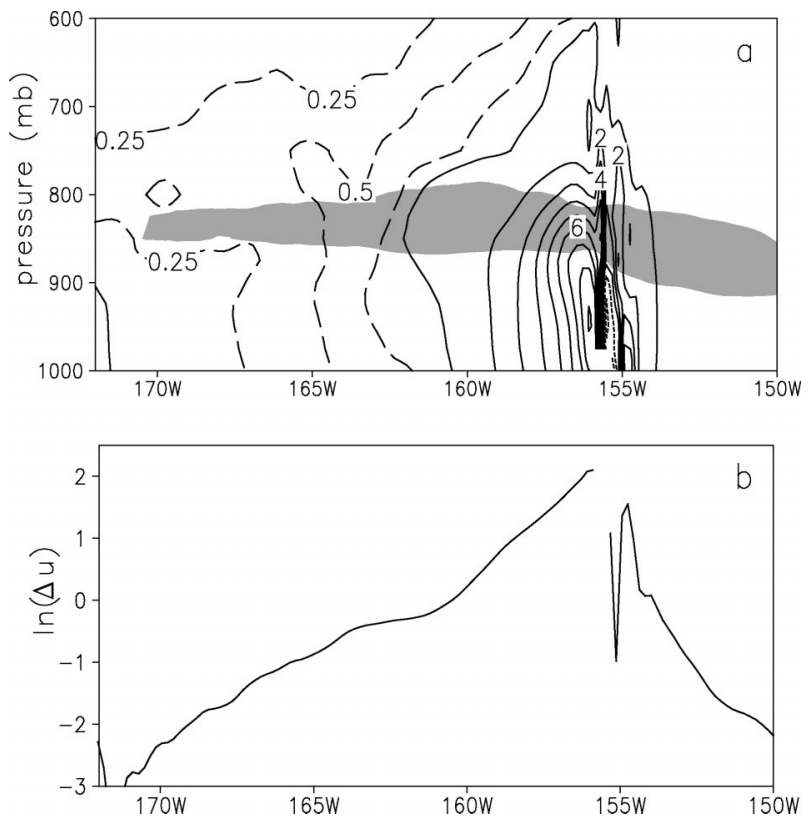

FIG. 10. Zonal wind deficit due to orographic forcing: $\Delta u=U_{\text {control }}$ - $U_{\mathrm{NM}}$ averaged between $19^{\circ}$ and $20^{\circ} \mathrm{N}$ (a) as function of longitude and pressure and (b) in logarithm at the surface. Area with cloud liquid water content greater than $0.15 \mathrm{~g} \mathrm{~kg}^{-1}$ is shaded. 
graphic effect. Over and immediately leeward of the islands, mountains act to reduce the cloudiness and precipitation probably due to orographically induced downdraft. Southwest of the Big Island, however, the presence of mountains causes a well-defined cloud band that extends southwestward for $700 \mathrm{~km}$ in the model. This is caused by low-level convergence in the wake. Such a cloud line has been noted by Smith and Grubišić (1993, their Figs. 7 and 18) and visible sometimes from high points on the Big Island (G. Kiladis 2002, personal communication). The observed summer climatology of TMI cloud liquid water captures this cloud band with its characteristic southwest tilt, albeit with a somehow shorter length of $300 \mathrm{~km}$ (Fig. 6a). The zonal band of enhanced liquid water in the TMI climatology farther to the west in $18^{\circ}-20^{\circ} \mathrm{N}$, on the other hand, is most likely an effect of SST's banded structure as discussed in section 4b. (Orographically induced anomalies are negative, if anything, in the observed band of high cloud liquid water.)

\section{Summary}

We have used the regional atmospheric model MM5 to study the far-field effect of the elevated Hawaiian Islands, motivated by a recent satellite study. Forced by the observed SST at the sea surface and NCEP analysis on the lateral boundaries, the model reproduces the salient features of the observed subtropical trade wind system near Hawaii, including a trade inversion at 2-3 $\mathrm{km}$ and a cloud layer beneath. In particular, a wind wake is found to form lee of each of the major Hawaiian Islands, as in the QuikSCAT observations. The model generates a pair of counterrotating vortices leeward of the Big Island with a reversal of the trades at the center of the wake as observed by Smith and Grubišić (1993) in their aircraft surveys.

A pair of warm and cold SST bands are imposed in the model to mimic the advection by the eastward HLCC and the accelerated westward NEC, respectively, both being the ocean response to the orographically induced wind curl west of Hawaii (Xie et al. 2001). In the model, anomalous surface winds converge onto the warm SST west of Hawaii, much as observed by QuikSCAT. The model response is trapped within the inversion-capped PBL and dominated by the first baroclinic mode structure with horizontal winds reversing directions in the lower and upper halves of the PBL. There are a pair of meridional cells with rising motion over the warm SST band and downdrafts on the two sides, much like the tropospheric Hadley circulation with a much reduced vertical scale. At the rising branch over the warm SST band, the cloud layer thickens with increased cloud liquid water content, while cloud water decreases significantly both to the north and south, a cloud response observed by the TMI. As such, this cloud response exerts a negative feedback on the prescribed SST banded structure. The surface wind response, on the other hand, features decelerated (accelerated) northeasterly trades south (north) of the warm band, acting to move the warm band southward due to wind-induced changes in evaporation, a tendency seen in the observed SST structure. These results from this SST run support Xie et al.'s (2001) hypothesis that ocean current advection, through its SST effect, sustains the wind wake and zonal cloud band for a long distance west of Hawaii.

We have also examined the orographic effect in the far field, a deviation from most of previous wake studies that focus on the near field. In the near field, the wind wake decays rapidly at the sea surface at an $e$-folding zonal scale of $200 \mathrm{~km}$, much shorter than shallow-water model prediction. This suggests the importance of dissipation processes other than the surface drag. In the far field, the wind and pressure perturbations are roughly in geostrophic balance, indicative of the effect of quasigeostrophic Rossby waves. The Smith et al. (1997) theory for the far field is then extended to include the pressure adjustment and Rossby wave effects. The westward propagation of the Rossby wave is found to increase the wake length significantly (by 60\%) compared to the solution that does not include pressure perturbations.

While the model overestimates the mean cloud water, it reproduces the salient features of the observed cloud field. Our experiments help identify the SST and orographic effects on clouds. Overall, the mountains on Hawaii act to reduce the cloud amount over and lee of the islands. The windward cloud band (Smolarkiewicz et al. 1988) and the southwest-tilted lee cloud line (Smith and Grubišić 1993) of the Big Island are the exceptions due to aerodynamic effects of the high mountains. In addition to these cloud lines near the islands, the SST run results show that the far-field cloud band that extends all the way to the west of the date line is due to the SST-induced convergence.

Acknowledgments. The TMI data are obtained via FTP from Remote Sensing Systems and the QuikSCAT data from Jet Propulsion Laboratory. We thank Joel Nakamura for producing Fig. 1 and anonymous reviewers for comments that have led to improved presentation. This work is supported by NASA through its Grant NAG5-10045 and JPL contract 1216010, and Frontier Research System for Global Change.

\section{APPENDIX}

\section{Shallow-Water Theory}

The simple theory of wake length of Smith et al. (1997) neglects the pressure adjustment. The strong inversion in the subtropical atmosphere provides an effective waveguide to propagate pressure waves in the horizontal direction. Here we develop a shallow-water theory that allows pressure changes. Sufficiently far away from the mountains, pressure perturbations above 
the inversion are small. We use a shallow-water system to model the vertical-mean flow in the PBL:

$$
\begin{aligned}
\left(U \frac{\partial}{\partial x}+\varepsilon\right) u-f v & =-g^{\prime} \frac{\partial h}{\partial x} \\
\left(U \frac{\partial}{\partial x}+\varepsilon\right) v+f u & =-g^{\prime} \frac{\partial h}{\partial x} \\
\left(U \frac{\partial}{\partial x}+\varepsilon\right) h+H\left(\frac{\partial u}{\partial x}+\frac{\partial v}{\partial y}\right) & =0
\end{aligned}
$$

where $U$ is the background trade wind speed, $\varepsilon$ is the dissipation rate, $f=f_{0}+\beta y$ the Coriolis parameter, $g^{\prime}=g \delta \theta / \theta_{0}$ is the reduced gravity ( $\delta \theta$ is the potential temperature difference across the inversion layer), $H$ is the mean inversion height, and $h$ its upward displacement. For $\delta \theta=6 \mathrm{~K}, \theta_{0}=300 \mathrm{~K}$, and $H=2.5 \mathrm{~km}$, the phase speed of the long gravity wave $c=\left(g^{\prime} H\right)^{1 / 2}$ $=22 \mathrm{~m} \mathrm{~s}^{-1}$, and the Rossby radius of deformation $L_{R}$ $=c / f_{0}=450 \mathrm{~km}$, about the same as the meridional extent of the Hawaiian Island chain.

High-frequency inertia-gravity waves are highly damped and in the far field, geostrophy dominates as in Fig. 8. Because the Rossby number $U^{\prime} /\left(f_{0} L_{R}\right)=4.6$ $\times 10^{-2} \ll 1$ for typical wind perturbations of $1 \mathrm{~m} \mathrm{~s}^{-1}$, we may apply the quasigeostrophic approximation and obtain the following vorticity equation:

$$
\left(U \frac{\partial}{\partial x}+\varepsilon\right) h-c_{R} \frac{\partial h}{\partial x}-\left(U \frac{\partial}{\partial x}+\varepsilon\right) L_{R}^{2} \nabla^{2} h=0,
$$

where $c_{R}=\beta L_{R}^{2}$ is the phase speed of the long Rossby wave. The nondispersive longwave probably dominates the far field, where Eq. (A4) simplifies into

$$
\left(U \frac{\partial}{\partial x}+\varepsilon\right) h-c_{R} \frac{\partial h}{\partial x}=0 .
$$

Following Smith et al. (1997), we let $\varepsilon=2 C_{D} U / H$, the dissipation rate on the PBL-mean flow due to surface friction $\left(C_{D}\right.$ is the surface drag coefficient). Using the geostrophy relation, (A5) can be recast for orographically induced zonal wind perturbations

$$
\left(U-c_{R}\right) \frac{\partial u}{\partial x}=-\frac{2 C_{D} U}{H} u .
$$

For $c_{R}=0$, the solution is

$$
u=u_{B} \exp \left(-x / L_{o}\right)
$$

where $u_{B}$ is the wind perturbation immediately lee of the islands, and $L_{o}=H /\left(2 C_{D}\right)$. For typical values of $H$ $=2.5 \mathrm{~km}$ and $C_{D}=1.25 \times 10^{-3}$, the $e$-folding wake length is $L_{o}=1000 \mathrm{~km}$. Smith et al. (1997) obtain the solution (A7) by setting $g^{\prime}=0$ and $f=0$ in Eq. (A1).

With pressure perturbation allowed and beta effect considered, the general solution of (A6) is

$$
u=u_{B} \exp (-x / L)
$$

Now the wake length is given by

$$
L=L_{0}\left(1-c_{R} / U\right)=\left(1-c_{R} / U\right) H /\left(2 C_{D}\right) .
$$

For $U=-7 \mathrm{~m} \mathrm{~s}^{-1}, L / L_{0}=1.64$, namely, the Rossby wave propagation increases the wake length by $64 \%$ to $1640 \mathrm{~km}$ under typical conditions near Hawaii.

The above analysis seems in qualitative agreement with the full-model simulation in that the geostrophic perturbations propagate far to the west and dominate the far field. Quantitatively, however, the theory overestimates the wake length substantially (Fig. 10b). A major weakness in our estimate of the dissipation rate is that it includes only surface friction. Entrainment across the inversion and horizontal wave dispersion are some other processes that can cause more rapid decay of orographic effect in the zonal direction.

\section{REFERENCES}

Austin, G. R., R. M. Rauber, H. T. Ochs III, and L. J. Miller, 1996: Trade-wind clouds and Hawaiian rainbands. Mon. Wea. Rev., 124, 2126-2151.

Baines, P. G., 1987: Upstream blocking and airflow over mountains. Ann. Rev. Fluid. Mech., 19, 75-97.

Battisti, D. S., E. S. Sarachik, and A. C. Hirst, 1999: A consistent model for the large-scale steady surface atmospheric circulation in the Tropics. J. Climate, 12, 2956-2964.

Businger, S., R. McLaren, R. Ogasawara, D. Simons, and R. J. Wainscoat, 2002: Starcasting. Bull. Amer. Meteor. Soc., 83, 858-871.

Chen, Y.-L., and J. Feng, 2001: Numerical simulations of airflow and cloud distributions over the windward side of the island of $\mathrm{Ha}-$ waii. Part I: The effects of trade inversion. Mon. Wea. Rev., 129, 1117-1134.

Dudhia, J., 1993: A nonhydrostatic version of the Penn State/NCAR mesoscale model: Validation tests and simulation of an Atlantic cyclone and cold front. Mon. Wea. Rev., 121, 1493-1513.

Flament, P., S. Kennan, R. Lumpkin, M. Sawyer, and E. Stroup, 1998: The Ocean. Atlas of Hawaii, S. P. Juvik and J. O. Juvik, Eds., University of Hawaii Press, 82-86.

Giambelluca, T. W., and T. A. Schroeder, 1998: Climate. Atlas of Hawaii, S. P. Juvik and J. O. Juvik, Eds., University of Hawaii Press, 49-59.

Gill, A. E., 1980: Some simple solutions for heat-induced tropical circulation. Quart. J. Roy. Meteor. Soc., 106, 447-462.

Grell, G. A., J. Dudhia, and D. R. Stauffer, 1994: A description of the fifth-generation Penn State/NCAR mesoscale model (MM5). NCAR Tech. Note NCAR/TN-398+STR, 117 pp.

Grubišić, V., R. B. Smith, and C. Shär, 1995: The effect of bottom friction on shallow-water flow past an isolated obstacle. J. Atmos. Sci., 52, 1985-2005.

Hashizume, H., S.-P. Xie, M. Fujiwara, M. Shiotani, T. Watanabe, Y. Tanimoto, W. T. Liu, and K. Takeuchi, 2002: Direct observations of atmospheric boundary layer response to SST variations associated with tropical instability waves over the eastern equatorial Pacific. J. Climate, 15, 3379-3393.

Hong, S.-Y., and H.-L. Pan, 1996: Nonlocal boundary layer vertical diffusion in a medium-range forecast model. Mon. Wea. Rev., 124, 2322-2339.

Kain, J. S., and J. M. Fritsch, 1993: Convective parameterization for mesoscale models: The Kain-Fritsch scheme. The Representation of Cumulus Convection in Numerical Models, Meteor. Monogr., No. 46, Amer. Meteor. Soc., 165-170.

Kobashi, F., and H. Kawamura, 2001: Variations of sea surface height at periods of 65-220 days in the subtropical gyre of the North Pacific. J. Geophys. Res., 106, 26 817-26831. 
Lin, Y.-L., R. D. Farley, and H. D. Orville, 1983: Bulk parameterization of the snow field in a cloud model. J. Climate Appl. Meteor., 22, 1065-1092.

Lindzen, R. S., and S. Nigam, 1987: On the role of sea surface temperature gradients in forcing low-level winds and convergence in the Tropics. J. Atmos. Sci., 44, 2418-2436.

Liu, Q., S. Wang, Q. Wang, and W. Wang, 2003: On the formation of Subtropical Countercurrent to the west of the Hawaiian Islands. J. Geophys. Res., 108, 3167, doi:10.1029/2002JC001366.

Liu, W. T., X. Xie, P. S. Polito, S.-P. Xie, and H. Hashizume, 2000: Atmospheric manifestation of tropical instability waves observed by QuikSCAT and Tropical Rain Measuring Mission. Geophys. Res. Lett., 27, 2545-2548.

Matsuno, T., 1966: Quasi-geostrophic motions in the equatorial area. J. Meteor. Soc. Japan, 44, 25-43.

Mlawer, E. J., S. J. Taubman, P. D. Brown, M. J. Iacono, and S. A. Clough, 1997: Radiative transfer for inhomogeneous atmosphere: RRTM, a validated correlated- $k$ model for the longwave. J. Geophys. Res., 102, 16 663-16 682.

Nickerson, E. C., and M. A. Dias, 1981: On the existence of atmospheric vortices downwind of Hawaii during the HAMEC project. J. Appl. Meteor., 20, 868-873.

Qiu, B., D. A. Koh, C. Lumpkin, and P. Flament, 1997: Existence and formation mechanism of the North Hawaiian Ridge Current. J. Phys. Oceanogr., 27, 431-444.

Rasmussen, R. M., P. Smolarkiewicz, and J. Warner, 1989: On the dynamics of Hawaiian cloud bands: Comparison of model results with observations and island climatology. J. Atmos. Sci., 46, 1589-1608.

Reisner, J. M., and P. K. Smolarkiewicz, 1994: Thermally forced low
Froude number flow past three-dimensional obstacles. J. Atmos. Sci., 51, 117-133.

Scorer, R. S., 1986: Cloud Investigation by Satellite. Ellis Horwood Ltd., Halsted Press, 300 pp.

Smith, R. B., and V. Grubišić, 1993: Aerial observations of Hawaii's wake. J. Atmos. Sci., 50, 3728-3750.

—_ A. C. Gleason, P. A. Gluhosky, and V. Grubišić, 1997: The wake of St. Vincent. J. Atmos. Sci., 54, 606-623.

Smolarkiewicz, P., R. M. Rasmussen, and T. L. Clark, 1988: On the dynamics of Hawaiian cloud bands: Island forcing. J. Atmos. Sci., 45, 1872-1905.

Thomson, R. E., J. F. R. Gower, and N. W. Bowker, 1977: Vortex streets in the wake of the Aleutian Islands. Mon. Wea. Rev., 105, 873-884.

Tompkins, A. M., and G. C. Craig, 1999: Sensitivity of tropical convection to sea surface temperature in the absence of large-scale flow. J. Climate, 12, 462-476.

Ueyoshi, K., and Y.-J. Han, 1991: A three-dimensional simulation of airflow and orographic rain over the island of Hawaii. J. Meteor. Soc. Japan., 69, 127-152.

Wentz, F. J., C. Gentemann, D. Smith, and D. Chelton, 2000: Satellite measurements of sea-surface temperature through clouds. Science, 288, 847-850.

Xie, S.-P., 1999: A dynamic ocean-atmosphere model of the tropical Atlantic decadal variability. J. Climate, 12, 64-70.

_, W. T. Liu, Q. Liu, and M. Nonaka, 2001: Far-reaching effects of the Hawaiian Islands on the Pacific ocean-atmosphere system. Science, 292, 2057-2060.

Yu, Z., N. Maximenko, S.-P. Xie, and M. Nonaka, 2003: On the termination of the Hawaiian Lee Countercurrent. Geophys. Res. Lett., 30, 1215, doi:10.1029/2002GL016710. 